\title{
OS USOS DO DIREITO E A QUESTÃO SOCIAL EM EVARISTO DE MORAES
}

Arley Fernandes Teixeira*

Resumo: O objetivo desse artigo é comparar e discutir o papel destinado ao direito e à legislação social pela doutrina jurídica socialista em dois momentos distintos da história recente: no início do século XX no Brasil, através especialmente de Evaristo de Moraes, e nos debates recentes acerca da crise dos direitos sociais, em especial através propostas de uso tático do direito do trabalho e direito insurgente. As conclusões demonstram como Evaristo de Moraes, ainda que seja considerado um jurista com uma postura combativa e crítica à época, entendia o direito como um espaço para transformação das condições urbanas e sociais, rejeitando, à princípio, técnicas revolucionárias, como a greve. Por outro lado, essas teorias dos usos do direito mais recentes entendem, a partir de toda a experiência jurídica proporcionada pelo século XX, o direito como um espaço de dominação e pacificação social e rejeitam, em parte, o seu papel transformador, não obstante, possa proporcionar ganhos pontuais.

Palavras-chave: Direito do trabalho; Usos do direito; História do Brasil; Evaristo de Moraes.

\section{THE USES OF LAW AND THE SOCIAL QUESTION IN EVARISTO DE MORAES}

\begin{abstract}
The objective of this article is to compare and discuss the role assigned to law and social legislation by socialist legal doctrine at two distinct moments in recent history: at the beginning of the 20th century in Brazil, especially through Evaristo de Moraes, and in recent debates about the crisis of social rights, especially through proposals for the tactical use of labor law and insurgent law. The conclusions demonstrate how Evaristo de Moraes, even though he is considered a jurist with a combative and critical posture at the time, understood law as a space for the transformation of urban and social conditions, rejecting, at first, revolutionary techniques such as the strike. On the other hand, these more recent theories of the uses of law understand, from all the legal experience provided by the 20th century, law as a space for domination and social pacification and reject, in part, its transformative role, even though it may provide occasional gains.
\end{abstract}

Keywords: Labor law; Legal uses; Brazilian history; Evaristo de Moraes.

\section{LOS USOS DEL DERECHO Y LA CUESTIÓN SOCIAL EN EVARISTO DE MORAES}

Resumen: El objetivo de este artículo es comparar y discutir el papel asignado al derecho y a la legislación social por la doctrina jurídica socialista en dos momentos distintos de la historia reciente: a principios del siglo XX en Brasil, particularmente a través de Evaristo de

\footnotetext{
* Bacharel e Mestrando em Direito pela Universidade Federal de Minas Gerais, Brasil, com bolsa pela FAPEMIG e membro do Studium Iuris (Grupo de Pesquisa em História da Cultura Jurídica da UFMG). ORCID: https://orcid.org/0000-0002-0964-5011. Contato: arleyft96@gmail.com
} 
Moraes, y en los recientes debates sobre la crisis de los derechos sociales, particularmente a través de las propuestas de uso táctico del derecho del trabajo y del derecho insurgente. Las conclusiones demuestran cómo Evaristo de Moraes, a pesar de ser considerado un jurista con una postura combativa y crítica en la época, entendía el derecho como un espacio para la transformación de las condiciones urbanas y sociales, rechazando, en un principio, técnicas revolucionarias como la huelga. Por otro lado, estas teorías más recientes sobre los usos del derecho entienden, a partir de toda la experiencia jurídica aportada por el siglo XX, el derecho como un espacio de dominación y pacificación social y rechazan, en parte, su papel transformador, aunque pueda aportar ganancias puntuales.

Palabras clave: Derecho laboral; Usos legales; Historia de Brasil; Evaristo de Moraes.

\section{Introdução}

O século XXI está sofrendo os efeitos de uma série de transformações na formatação do Estado Social ocorridas a partir do final do século XX. Com a virada neoliberal nos anos 1990, o Estado passa a flexibilizar os chamados direitos sociais, ou direitos de segunda geração. Com o aumento da terceirização, da informalidade e dos contratos parciais, além da exigência de um setor público mais ágil e empresarial, há uma verdadeira onda de corte de gastos ${ }^{1}$. Acrescente-se a isso a chamada crise do neoextrativismo, que ganha força a partir dos primeiros anos do século XXI na América Latina, aproveitando o que Maristella Svampa chama de "consenso das commodities", isto é, uma nova dinâmica econômica que tende a uma reconfiguração da produção econômica, valorizando atividades primárias extrativistas, que traz consigo uma série de consequências ambientais e sociais devastadoras ${ }^{2}$. Esse conjunto de transformações econômicas e sociais é um dos principais fatores para uma verdadeira crise de confiança acerca da efetividade dos direitos sociais e do próprio direito em seu papel transformador.

Nesse contexto, teorias críticas socialistas sobre o direito, como as que serão analisadas nesse artigo, sobre o uso tático do direito do trabalho e sobre o direito insurgente, vêm propondo alternativas teóricas e práticas. Em um cenário de descrédito do Estado e dos direitos sociais, a crítica recai, especialmente, sobre a função pacificadora desses direitos de segunda geração, em seus aspectos essencialmente limitados.

Retornemos um pouco no tempo até os primeiros anos do século XX. Também ali ocorria uma revolução no mundo jurídico e nas formas de produção econômica. Com a

\footnotetext{
${ }^{1}$ KUNTZ, Rolf. Os direitos sociais em xeque. Lua Nova: Revista de Cultura e Política, n. 36, 1996, p. 156.

${ }^{2}$ SVAMPA, Maristella. As fronteiras do neoextrativismo na América Latina: conflitos socioambientais, digo ecoterritorial e novas dependências. São Paulo: Elefante, 2019, p. 36.
} 
industrialização, proporcionada pela Revolução Industrial, o trabalho urbano começa a se tornar economicamente relevante nos países ocidentais. Especialmente no Brasil, ainda que a indústria ocupe apenas 3,4\% da população economicamente ativa em 1900 (o que é pouco se comparado com os $13,8 \%$ de 1920$)^{3}$, há uma grande mudança na configuração dos conflitos e também nas movimentações sociais decorrentes dessas disputas. Todo esse conjunto de problemas, políticos e jurídicos, e as transformações na relação entre indivíduo e trabalho é o que chamamos aqui de questão social. Ao longo das duas primeiras décadas do século XX no Brasil, a questão social é central para a compreensão do país daquele período, com suas repercussões políticas e jurídicas. É nesse contexto que o direito do trabalho começa a se revelar, destacando-se do direito civil pelo seu aspecto protetivo e de fuga de um ideário abstrato e igualitário.

Em meio a essas tensões nascentes nas primeiras décadas do novecentos, sobretudo nas cidades com grande concentração de indústrias, como Rio de Janeiro e São Paulo, há também uma preocupação intelectual e política acerca de como lidar com esses problemas. Como aponta a historiografia, em especial Ângela de Castro Gomes ${ }^{4}$ e Boris Fausto ${ }^{5}$, uma dessas correntes, dentro do ambiente operário, são os socialistas, cujo principal representante no ambiente jurídico é Evaristo de Moraes (1871-1939).

O objetivo deste artigo, portanto, é compreender como esses dois pólos se relacionam, em suas diferenças e semelhanças, sobre aspectos como o uso do direito do trabalho pelas classes operárias, a importância de uma legislação social e o papel do Estado na mediação do conflito entre classes. Essa perspectiva nos permite não apenas compreender melhor o cenário do direito do trabalho no início do século XX, como também inserir a perspectiva atual trabalhista em uma lógica histórica e não linear. Por fim, a ideia é traçar hipóteses para as possíveis diferenças encontradas, que poderão ser confirmadas em pesquisa mais aprofundada, que permita seguir a linha dessa tradição jurídica ao longo do século XX e XXI.

Para tanto, as principais fontes que utilizei neste trabalho são os textos de Evaristo de Moraes sobre direito do trabalho, sobretudo Apontamentos de Direito Operário, de 1905, além de artigos seus no Correio da Manhã, periódico publicado no Rio de Janeiro de 1901

\footnotetext{
${ }^{3}$ FAUSTO, Boris. Trabalho urbano e conflito social. Rio de Janeiro: Difel, 1977, p. 20.

${ }^{4}$ GOMES, Ângela Maria de Castro. Burguesia e trabalho: política e legislação social no Brasil 1917-1937. Rio de Janeiro: Editora Campus LTDA., 1979.

${ }^{5}$ FAUSTO. Trabalho urbano e conflito social, cit.
} 
até 1971, além dos textos de Gustavo Seferian e Ricardo Prestes Pazello sobre os usos do direito do trabalho, que serão objeto da comparação.

\section{Os direitos sociais em crise: uso tático e insurgente do direito do trabalho no} século XXI

Todo contexto de crise demanda uma nova perspectiva teórica e prática para lidar com os novos problemas e desafios postos. O século XXI tem sido até o momento um período marcado por crises sociais, econômicas, políticas e ambientais, e essas novas perspectivas socialistas vêm se tornando uma importante voz crítica dentro do ambiente jurídico acadêmico.

Especificamente sobre o direito do trabalho, os desafios se mostram ainda mais fortes. Desde o nascimento ligado aos direitos sociais, que são um produto e síntese do século XX, o direito do trabalho é um foco de disputa em aberto nesse momento atual. São vários os exemplos recentes disso, desde a Reforma Trabalhista e da Previdência em 2017 e 2019, respectivamente, e pelo desmonte do Ministério do Trabalho e da Justiça do Trabalho nos últimos $\operatorname{anos}^{6}$. Em uma perspectiva mais ampla, vemos ainda o progressivo avanço do neoextrativismo no Brasil e seus impactos sociais para os trabalhadores. Todo esse movimento de rediscussão do papel do direito do trabalho, do Estado e da legislação social como um todo é um foco de tensão atualmente, um verdadeiro centro no qual se debatem aspectos específicos, como o problema do neoextrativismo, da Reforma Trabalhista e Previdenciária.

Não é o foco deste artigo discutir qualquer uma dessas questões especificamente. O objetivo desse tópico, inserido em uma perspectiva maior do artigo, é olhar para as reações na doutrina jurídica em relação a esses conflitos, especificamente para duas iniciativas, em alguma medida, complementares: o uso tático do direito do trabalho e o direito insurgente. Qual o papel destinado ao direito nesse novo contexto?

A primeira dessas perspectivas, o uso tático do direito do trabalho, ou direito do trabalho como barricada, presente na obra de Gustavo Seferian, traz uma alternativa para a crise juslaboral a partir da compreensão de que o direito do trabalho, tal como pensado e projetado até então pela generalidade da doutrina jurídica, responde aos interesses burgueses e tem como função essencial a pacificação social. Nas palavras do autor:

\footnotetext{
${ }^{6}$ KREIN, José Darin. O desmonte dos direitos, as novas configurações do trabalho e o esvaziamento da ação coletiva: consequências da reforma trabalhista. Tempo Social, 2018, p. 77-104.
} 
Toda uma tradição (...) projeta na Legislação Trabalhista uma funcionalidade de efetivação da paz social e da harmonização da luta de classes - isso, claro, quando o leem a partir da compreensão de que vivemos no cerne de uma sociedade classista -, ou escoram suas funcionalidades em perspectivas descoladas da materialidade ou estruturalmente inalcançáveis no bojo da sociedade capitalista. Guinam o Direito do Trabalho, pois, consciente ou inconscientemente, para a atenção de interesses eminentemente burgueses? ${ }^{7}$.

Essa premissa da qual parte Seferian, de que a doutrina jurídica entende o direito do trabalho como um ambiente de pacificação social e que, consciente ou inconscientemente, o leva para os interesses burgueses, ajuda a explicar o que é o direito do trabalho como barricada. Em contraposição, portanto, a esse entendimento, o autor explica que o uso tático do direito do trabalho fundamenta-se na ideia de que o papel do direito não é de pacificação, ou estabilização social, mas de acirramento das disputas políticas, "tornando mais pulsantes

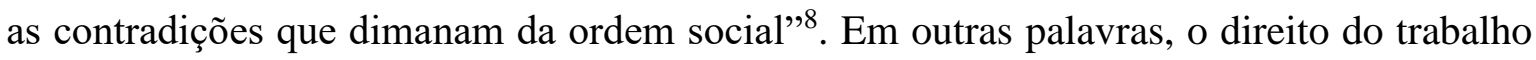
deve servir aos interesses dos trabalhadores, ser um meio de transformação da realidade social, apesar de inserido em um contexto maior de controle social.

Essa análise proposta por Seferian relaciona-se, ainda que indiretamente, com a interpretação proposta por Pietro Costa acerca do papel duplo do Estado durante a formação dos direitos sociais. Se por um lado, no início do século XX, há um fortalecimento do aparato administrativo do Estado no sentido de acrescentar junto às leis civis um direito novo, preocupado e consciente dos problemas sociais decorrentes da industrialização; por outro lado, esse mecanismo pretendia governar e controlar os nascentes sujeitos sociais e políticos. O Estado Social é, nesse contexto, um aparato criado para o controle das massas ${ }^{9}$.

Partindo disso e ampliando a percepção, Seferian afirma que a sua proposta de direito do trabalho tem um fim desejado, que é a sua superação. Ou seja, apenas com a superação do direito, sobretudo do direito do trabalho, ocorreria a revolução que beneficiaria os trabalhadores ${ }^{10}$. Até esse estágio, porém, entende o autor que é possível conseguir bons resultados utilizando-se desse aparato estatal ${ }^{11}$. Apesar de Costa não adentrar propriamente na questão do direito como instrumento burguês, a percepção do duplo papel do Estado está também presente na análise de Seferian; enquanto o direito entendido como instrumento de

\footnotetext{
${ }^{7}$ SEFERIAN, Gustavo. Direito do trabalho como barricada: sobre o uso tático da proteção jurídica das trabalhadoras e trabalhadores. Belo Horizonte: RTM, 2021, p. 85.

${ }^{8}$ Idem.

${ }^{9}$ COSTA, Pietro. I diritti sociali: un diagramma del loro sviluppo. In: CAPELLINI, Paolo; COSTA, Pietro; FIORAVANTI, Maurizio, et al. Iuris Quidditas: liber amicorum per Bernardo Santalucia. Napoli: Editoriale Scientifica, 2011, p. 44.

${ }^{10}$ SEFERIAN. Direito do trabalho como barricada, cit., p. 105.

${ }^{11}$ Ibidem, p. 99.
} 
controle das massa não se rompa definitivamente, é possível utilizar-se dele para conseguir saltos políticos, ainda que limitados.

Aplicando essa teoria dentro de uma questão específica, como o neoextrativismo, por exemplo, podemos verificar alguns aspectos interessantes. O próprio Gustavo Seferian nos dá indicações dessa aplicação, sobretudo em artigo intitulado Onze proposições sobre o direito do trabalho desde a perspectiva ecossocialista. A primeira indicação está na segunda proposição: a revolução do século XXI reclama um novo e transicional direito do trabalho. A ideia aqui é a de que o direito do trabalho tradicional, tal como conhecemos, formado em um contexto em que a preocupação ambiental não era central, não consegue lidar bem com as novas questões ecológicas colocadas. É preciso, portanto, uma nova perspectiva protetiva, que abarque o amparo ao trabalhador em uma dimensão coletiva mais ampla ${ }^{12}$. Outra indicação importante que ajuda a entender os fins do direito do trabalho como barricada é a sétima proposição: pensar taticamente o direito do trabalho desde o direito ambiental. Nesse ponto, é interessante verificar como Seferian conecta direito do trabalho e direito ambiental, de forma que as discussões propostas por esse último possam ser utilizadas taticamente dentro dos debates juslaborais, em uma aplicação do chamado uso tático do direito ${ }^{13}$. Ou seja, o direito ambiental, ainda que essencialmente não possa resolver, de fato, o problema ecológico, ele traz ferramentas interessantes, que se utilizadas taticamente podem trazer avanços.

Perspectiva paralela e complementar a essa, também inserida na discussão sobre a recente crise do direito social e do direito do trabalho, é a proposta do direito insurgente, de Ricardo Prestes Pazello. Em uma perspectiva mais geral, não apenas relativa ao direito do trabalho, Pazello afirma que o direito insurgente é um método de resistência, "enquanto predomina a assimetria de poderes" ${ }^{\prime 14}$, em que há combinação de dois elementos: o uso tático do direito e uma estratégia de extinguibilidade. Ou seja, também para Pazello, assim como na perspectiva analisada anteriormente, o direito é limitado essencialmente em seu aspecto revolucionário e somente a sua extinção permitiria alcançar o fim último desejado.

Três elementos constituem a noção de direito insurgente: i) a formulação acerca da relação jurídica dependente, ligada às discussões acerca do giro descolonial, na qual os

\footnotetext{
12 SEFERIAN, Gustavo. Onze proposições sobre o Direito do Trabalho desde a perspectiva ecossocialista. Teoria Jurídica Contemporânea, v. 4, 2019b, p. 95-96.

${ }^{13}$ Ibidem, p. 102-103.

${ }^{14}$ PAZELLO, Ricardo Prestes. Direito insurgente: fundamentações marxistas desde a América Latina. Revista Direito e Práxis, v. 9, 2018, p. 1590.
} 
sujeitos tornados iguais ligam-se, através do consumo, a uma superexploração produzida por relações de centro-periferia; ii) a ideia de que o direito insurgente liga-se às relações sociais através dos movimentos populares; iii) a lógica de que o direito insurgente está contido entre a crítica do direito e a crítica marxista ao direito ${ }^{15}$. Isto é, de um lado, essa teoria entende o direito como arma de libertação do povo, em um uso estratégico, mas de outro lado utiliza também como inspiração uma crítica ao direito que não abre espaço para concessões, em um uso tático do direito.

Em linhas gerais podemos extrair em comum dessas duas teorias recentes algumas considerações sobre o papel do direito nesse momento atual de crise. A crítica ao direito, especialmente ao direito do trabalho, é o ponto mais claro de ambas. O direito é claramente entendido como um espaço de dominação estrutural e que não constitui elemento revolucionário. Apesar disso, a utilização desse espaço jurídico pode ser capaz de proporcionar ganhos políticos e deve por isso ser utilizado na causa. Isso é o que ambos denominam uso tático do direito, apesar das diferentes formas com as quais os autores definem o que constitui esse uso tático. Ou seja, o direito para ambos tem um papel duplo: i) proporcionar ganhos políticos específicos; ii) ser utilizado como forma de conseguir a sua própria extinção.

Pazello apresenta um quadro comparativo que é bastante interessante na intenção de classificar os diferentes usos políticos do direito, especialmente no que se refere à desejada transição do capitalismo para o socialismo, que é a premissa da qual ele parte ${ }^{16}$. De acordo com esse quadro, há quatro possíveis usos do direito, diante de uma perspectiva revolucionária.

O uso negativo, ou antinormativista anarquista, que é caracterizado por um verdadeiro abandono da luta política através do direito. O direito, por ser um aparato de dominação, assim como o próprio Estado, em nada pode ser útil para a perspectiva adotada, devendo por isso ser abandonado e rejeitado. Na visão do autor, essa postura seria insuficiente, visto que na fase de transição para o modelo socialista as relações mercantis permanecerão por um tempo.

O segundo uso político do direito é o que Pazello chamou de socialismo jurídico, que é também reconhecido como uso estratégico do direito. Essa ideia parte da noção de que o direito consegue ser capaz de responder às expectativas sociais, assim como a própria

\footnotetext{
15 Ibidem, p. 1591-1592.
}

${ }^{16}$ Ibidem, p. 1578. 
sociedade burguesa. Não há um desejo concreto de revolução, mas reformas políticas, jurídicas e sociais a fim de buscar reequilíbrios coletivos. O direito nesse contexto cumpre o seu papel básico de pacificação social e conciliação entre as classes, o que explica porque o autor também o classifica como insuficiente para uma postura revolucionária.

Por fim, dois últimos usos políticos do direito, que são entendidos como parte do processo de transição, por vezes complementares e utilizados em fases diferentes do processo revolucionário. $\mathrm{O}$ uso tático do direito, no qual, como explicado, o direito, ainda que entendido como estrutura de dominação, pode contribuir para o processo revolucionário utilizando-se da potencialidade da lei e na sua estrutura organizativa ${ }^{17}$. E o uso revolucionário do direito, presente, sobretudo, na obra de Pachukanis, utilizado em um contexto pós-revolucionário, mas ainda em transição, em que o direito vai trabalhar para cumprir o seu objetivo final: a sua extinção. Marx, em alguma medida, também se coloca nesse plano político do uso tático do direito, como na seguinte passagem de $O$ Capital:

[...] para 'se proteger' contra a serpente de suas aflições, os trabalhadores têm de se unir e, como classe, forçar a aprovação de uma lei, uma barreira social intransponível que os impeça a si mesmos de, por meio de um contrato voluntário com o capital, vender a si e a suas famílias à morte e à escravidão ${ }^{18}$.

Ambas as teorias citadas anteriormente, o direito do trabalho como barricada e o direito insurgente, classificam-se, como os próprios autores a fazem, dentro da perspectiva do uso tático do direito. Não se nega a capacidade do direito de transformar as condições sociais, mas não se prega a ingenuidade, como afirmam ocorrer no uso estratégico do direito, de acreditar que esse é o processo pensado para modificar as relações econômicas, sociais e jurídicas próprias do capitalismo.

\section{A questão social em Evaristo de Moraes: ingenuidade ou estratégia de} transformação social?

Voltemos um pouco no tempo até o início do século XX. Também ali, assim como hoje, passávamos por um momento de crise e desconfiança no direito, mas por razões muito diferentes da atual. Pietro Costa explica que ao final do século XIX, a retórica comum ao constitucionalismo antiabsolutista presente durante o século XVIII e parte do século XIX é subvertida, cedendo espaço para uma nova forma de se enxergar os sujeitos de direito e o

\footnotetext{
${ }^{17}$ Ibidem, p. 1574.

${ }^{18}$ MARX, Karl. O Capital [Livro I]: crítica da economia política. O processo de produção do capital. São Paulo: Boitempo, 2017, p. 373-374.
} 
Estado $^{19}$. O motor transformador dessa mudança foi a Revolução Industrial, que transformou o conflito social urbano, a relação da pobreza com a marginalização social. Explica $\operatorname{Costa}^{20}$ que:

\begin{abstract}
Muda a geografia social da pobreza porque ela não tem mais relação com os marginais e desenraizados, mas ameaça a vida cotidiana do proletariado: a nova classe social que vem se criando com a difusão da manufatura, com a invenção da nova célula produtiva, a fábrica. Adquire uma nova centralidade, em consequência da revolução industrial, o trabalho. Mudam a qualidade, a quantidade, as características estruturais e o impacto social do trabalho produtivo, e mudam os conflitos sociais inerentes a ele: os conflitos não são mais 'jacqueries' periféricas, improvisadas e efêmeras explosões de violência, mas se traduzem em tentativas e projetos de transformação político-social mais ou menos radical (Tradução livre).
\end{abstract}

Essa mudança na forma do conflito social, com a introdução dos operários urbanos como classe social a partir do século XIX, trouxe consigo uma série de problemas sociais, políticos e jurídicos, denominados em conjunto como questão social. É nesse contexto de tentar solucionar a questão social que o Estado modifica o seu papel e a sua atuação, através de medidas legislativas e administrativas. É aqui que surge o que os historiadores do direito, como o já citado Pietro Costa ${ }^{21}$ e, dentre outros, Giovanni Cazzetta ${ }^{22}$, chamam de lei social. A legislação social - que surge a princípio como uma legislação de exceção, para suprir possíveis lacunas ou ausência na legislação civil - ganha corpo ao longo dos primeiros 3/4 do século XX, até a sua fragilização a partir dos anos $1970^{23}$.

No Brasil, esse percurso da legislação social e da questão social nas primeiras décadas do século XX segue um caminho similar àquele vivenciado na Europa, não obstante algumas particularidades no processo de industrialização no Brasil, como a grande presença de mão de obra estrangeira, por exemplo. É justamente nesse contexto de transição, de rediscussão do papel do direito e sobre como lidar com a questão social que repousa minha análise.

Nesse período um nome é particularmente relevante no meio jurídico brasileiro no que diz respeito às questões operárias: Evaristo de Moraes. Ele já era conhecido da imprensa carioca desde o final do século XIX por dois casos especialmente interessantes, que ajudam a entender um pouco da personalidade de Moraes: a defesa do próprio pai em 1897, Basílio de Moraes, diretor do orfanato Santa Rita de Cássia e acusado de abuso sexual contra as

\footnotetext{
${ }^{19}$ COSTA. I diritti sociali: un diagramma del loro sviluppo, cit.

${ }^{20}$ Ibidem, p. 40.

${ }^{21}$ Ibidem.

${ }^{22}$ CAZZETTA, Giovanni. Lei e Estado Social: da legislação operária aos dilemas do welfare-sem lei. Revista da Faculdade de Direito da UFRGS, Porto Alegre, n. 41, dez. 2019.

${ }^{23}$ Ibidem, p. 33.
} 
meninas que abrigava; e o caso das "madalenas impenitentes", como ficou conhecido, no qual Moraes impetrou Habeas Corpus a favor de prostitutas no Rio de Janeiro, a fim de protegê-las das prisões ilegais e assegurar que pudessem habitar as áreas que estavam sendo desocupadas.

De acordo com Joseli Maria Nunes Mendonça, autora de estudo biográfico sobre o autor, esses dois casos ajudam a compreender o papel de Evaristo de Moraes como figura pública na Primeira República: um intelectual dos casos complexos e polêmicos - o do pai ou que envolviam a defesa dos oprimidos - a questão das prostitutas ${ }^{24}$. Uma dicotomia interessante, que ajuda a entender o alcance da figura de Evaristo de Moraes nesse contexto, tanto no sentido acadêmico e intelectual, como uma figura que pensava as questões sociais e políticas do Brasil, e também como um ativo representante da classe operária e defensor dos oprimidos. Em ambos os seus aspectos, ele certamente era, nesse contexto, de alguma forma, uma liderança no cenário político e jurídico brasileiro, sobretudo em sua atuação na questão operária.

Durante os primeiros anos do século XX, mais precisamente em 1903, Evaristo de Moraes começou a publicar, nas páginas do Correio da Manhã, alguns capítulos daquilo que se tornaria, em 1905, o livro Apontamentos de Direito Operário. Esse livro reunia, em seus nove capítulos, temas de direito operário considerados na época como pontos essenciais a serem reformados na legislação brasileira, tais como a questão dos acidentes de trabalho, greves, trabalho feminino e infantil, carga horária diária de trabalho, entre outros.

A lógica presente no pensamento de Evaristo de Moraes, que permeia quase todos os capítulos do livro, é a de que o direito civil, com sua "velha" estrutura liberal, não era mais capaz de suportar o peso das mudanças sociais. A crença na liberdade contratual e de trabalho, de acordo com Moraes fazia com que a velha literatura jurídica nacional não aceitasse regras que pudessem fixar a relação entre empregado e empregador ${ }^{25}$. É nesse contexto então que, em linhas gerais, o autor propõe reformas básicas, que são destrinchadas especificamente em cada capítulo, de forma a se abrir espaço para a intervenção do poder público, criando determinados institutos jurídicos com o objetivo principal de proteger a classe trabalhadora. Ou seja, Moraes aqui já delimita aquilo que será ao longo dos anos seguintes a linha mestra do direito do trabalho: o seu sentido de proteção.

\footnotetext{
${ }^{24}$ MENDONÇA, Joseli Maria Nunes. Evaristo de Moraes: tribuno da República. Campinas: UNICAMP, 2007, p. 65.

${ }^{25}$ MORAES, Evaristo de. Apontamentos de direito operário. $3^{\mathrm{a}}$ ed [1 ${ }^{\mathrm{a}}$ ed. 1905]. São Paulo: LTr, 1986, p. 9.
} 
Para os fins deste artigo, vou me ocupar sobretudo do papel que é destinado ao direito nesse período de transformação social. Isto é, como Evaristo de Moraes entendia a função que as normas jurídicas poderiam proporcionar à resolução dos problemas operários, seja em seu sentido revolucionário ou pacificador social.

Logo no capítulo terceiro de Apontamentos de Direito Operário já temos um indício de como Evaristo de Moraes pensava essa questão. Nesse trecho do livro ele discute o trabalho infantil nas fábricas, questão que já tinha sido objeto do Decreto 1.313/1891, que regulamentava as condições em que crianças e adolescentes poderiam realizar trabalho industrial no Brasil. Durante todo o capítulo, o intuito de Moraes é bem claro: mostrar como o Brasil deveria pensar a reforma da sua legislação sobre o tema, tendo em vista a experiência europeia. Isto é, a solução para a nossa questão estava na mudança da legislação, adaptandoa às mais modernas previsões europeias. Ao final do capítulo, Moraes ainda faz uma breve indicação de como ele pensava o problema das greves, afirmando que, apesar de com elas os operários conseguiram algumas vitórias momentâneas, "passada a agitação, satisfeita a necessidade momentânea, tudo se esquece!"26.

Sobre o problema dos acidentes de trabalho, a questão gira em torno da ausência de regulação sobre o tema, que estava à mercê da responsabilidade civil tradicional, própria do direito civil. Esse capítulo, o quarto do livro, segue uma lógica similar àquela do anterior, isto é, Moraes apresenta as principais legislações presentes na Europa e, ao final, conclui que o melhor caminho a ser adotado pelo Brasil para resolver o problema deveria ser o da alteração da legislação sobre o tema, criando-se um regime de indenização que não dependeria da comprovação de culpa do patrão pelo acidente ${ }^{27}$.

Também nas questões relativas à carga horária diária de trabalho e da formação dos sindicatos, Moraes adota uma solução pautada sobre o direito, da necessidade de reforma da legislação nacional para atender aquilo que de melhor estava sendo pensado na Europa e nos países com maior presença operária e industrial. No caso da carga horária diária, a lógica defendida por Moraes é a de que a sua diminuição evitaria a fadiga do trabalhador, diminuindo os riscos e, portanto, aumentando a produção ${ }^{28}$. Ou seja, menor carga horária não necessariamente resultaria em menor produção. No caso dos sindicatos e cooperativas, a solução apontada por Evaristo de Moraes demonstra um pouco de como ele pensava a

\footnotetext{
${ }^{26}$ Ibidem, p. 36.

${ }^{27}$ Ibidem, p. 46.

${ }^{28}$ Ibidem, p. 84-85.
} 
questão da radicalização do movimento operário, através das greves e manifestações. Os sindicatos e cooperativas operárias, para o autor, seriam uma forma de pacificação social e coletivização das reivindicações, em oposição às greves, que seria um recurso extremo e perigoso. Nas palavras de Moraes:

\begin{abstract}
A evolução do movimento operário mostra que a greve precede o sindicato: no princípio, porém, o sindicato é quase tão somente dedicado à preparação da greve. Mas, como se viu na Inglaterra e nos Estados Unidos, essa fase não dura muito. A ela sucede o período da verdadeira organização profissional, em que os sindicatos se transformam em instrumentos de paz social e de educação operária. À medida que os sindicatos se tornam mais fortes e mais ricos, vão compreendendo que podem tratar pacificamente com os capitalistas as condições do trabalho assalariado, sem socorrer-se do recurso extremo da greve ${ }^{29}$.
\end{abstract}

Evaristo de Moraes entende os sindicatos e cooperativas como estágio de evolução posterior às greves. O operário, somente sindicalizado, ou seja, incluído dentro da lógica jurídica e por ela controlado, seria educado e pacificado. É isso que escreve Seferian quando aponta que Evaristo de Moraes entende o operário isolado como frágil, enquanto o "obreiro sindicalizado" é aquele que faria valer seus interesses ${ }^{30}$. Porém, argumenta Seferian, é justamente o operário sindicalizado que serve aos interesses capitalistas na sua missão de pacificação social.

É interessante perceber nesses exemplos como Moraes pensa o direito, especialmente o direito do trabalho, como uma missão pacificadora da experiência operária. As greves para Evaristo de Moraes seriam um artifício perigoso e pouco prático para a solução dos problemas urbanos. As sínteses de quase todos os capítulos de Apontamentos de Direito Operário apontam para respostas internas ao direito, rejeitando soluções extremas como as defendidas, na época, pelos movimentos anarquistas ${ }^{31}$.

Na classificação proposta por Pazello, e explicada anteriormente, a argumentação proposta por Evaristo de Moraes certamente seria classificada como uso estratégico do direito, ou socialismo jurídico, isto é, a percepção de que o direito pode solucionar os problemas de determinada questão social, rejeitando soluções externas ao direito ou mais extremas, como o caso das greves.

\footnotetext{
${ }^{29}$ Ibidem, p. 96.

${ }^{30}$ SEFERIAN Scheffer Machado, Gustavo. Muito mais que "estudinhos": matriz privada do Direito do Trabalho e a atualidade dos "apontamentos de direito operário" de Evaristo de Moraes. In: PIOVESANA, C.U.M. et alii. (Org.). Seminário quem é quem no Direito do Trabalho. 1ed. São Paulo: LTr, v. 1, 2019a, p. 20.

${ }^{31}$ Sobre a questão dos anarquistas, conferir: FAUSTO. Trabalho urbano e conflito social, cit.; DECCA, Edgar S.. Ensaio sobre a memória anarquista: a história como ficção coletiva. História Oral, Rio de Janeiro, v. 2, p. 111-134, 1999; ZANIRATO, Silvia Helena. O descanso do guerreiro: um estudo sobre a instituição da Previdência Social no Brasil. Maringá: EdUem, 2003.
} 
No quinto capítulo do Apontamentos, Moraes discute justamente a questão das greves e, especificamente a esse respeito, é interessante perceber o posicionamento do autor, fugindo do padrão dos outros capítulos do restante da obra. $\mathrm{O}$ autor, ainda que apontando a greve como "arma perigosa do partido revolucionário-econômico"32, entende que a legislação nacional, sobretudo o Código Penal de 1890 e o Decreto n. 1.162/1890 não proíbem as greves, de forma que o direito à realização das greves no Brasil estava plenamente reconhecido pela ordem jurídica. É preciso entender que, nesse contexto, a questão que se coloca sobre as greves não é a da regulamentação, mas apenas a não proibição, como aponta Evaristo de Moraes. Isto é, bastava uma atitude negativa por parte do Estado, a não proibição da decisão coletiva dos operários de não trabalhar.

Nesse ponto, Moraes vai além do mero reconhecimento da solução jurídica, visto que, como explicado pelo próprio autor, a legislação nacional já reconhecia o direito à greve. O ponto colocado, portanto, é material: apesar de permitido, o direito à greve era constantemente ameaçado nas manifestações operárias. Evaristo de Moraes, então, em função do desrespeito à legislação, critica a atuação policial, do Poder Executivo e do Poder Judiciário. Em síntese, portanto, sobre esse ponto especificamente, apesar de discordar politicamente da sua utilização, como deixa claro no livro em diversos trechos, dado o aspecto revolucionário da greve, Evaristo de Moraes entende que a não proibição dela pela legislação, isto é, a solução jurídica, não teria sido suficiente, tendo em vista os constantes abusos na prática policial e administrativa.

Em artigo publicado no Correio da Manhã, no período de realização da greve dos cocheiros e carroceiros, em 1906, Evaristo de Moraes critica severamente a prática das delegacias de polícia, afirmando que operários têm seus direitos recorrentemente violados pelas autoridades públicas, o que reflete os vícios e defeitos próprios da sociedade brasileira. No momento em que inicia uma greve, a situação se complica ainda mais:

\begin{abstract}
Declarada uma greve, a situação se torna ainda mais melindrosa. O mal-estar que atinge a todas as autoridades as predispõe para o arbítrio e para a ilegalidade. As ordens violentas vêm, muitas vezes, de cima, de onde não deviam partir. Decretase uma espécie de estado de sítio para uso da polícia e em prejuízo do operário. Então se vê, em plena luz e sem possibilidade de dúvidas, a triste condição em que vive o trabalhador nessa República feita pelos moldes norte-americanos ${ }^{33}$.
\end{abstract}

Em outro texto, publicado no mesmo Correio da Manhã, no dia 18 de agosto de 1906, Evaristo Moraes tece mais críticas à atuação policial:

\footnotetext{
${ }^{32}$ MORAES. Apontamentos de direito operário, cit., p. 49.

${ }^{33}$ CORREIO DA MANHÃ. Rio de Janeiro. n. 1.996, 29 dezembro, 1906b, p. 3.
} 
(...) toda ação policial é atentatória dos direitos constitucionais, somente exprimindo a parcialidade do poder público, posto assim, sem disfarce, ao lado do capitalismo. De testemunha e indiferente, diante de conflito entre o Capital e o Trabalho, a Polícia se transforma em partidária do mais forte, ajudando-o na sua obra de opressão e de extorsão... E a cegueira é tamanha, a desorientação tão flagrante, que chega a reviver um dispositivo morto, reprimindo, com abuso de poder e manifesta ilegalidade, um ato lícito, que é a expressão de um direito! ${ }^{34}$.

Em síntese, portanto, no ponto específico do direito de greve, Evaristo de Moraes tem uma postura diferente: admite que a previsão legal não é suficiente, ainda que não entenda que seja possível uma modificação dessa realidade por medidas drásticas ou revolucionárias, e critica as recorrentes violações legais praticadas pela polícia. É evidente que a postura diferente do autor nesse ponto específico dá-se por um motivo bem simples: a greve não exige mais qualquer intervenção legislativa por parte do Estado, bastando que se faça cumprir o que já está previsto na lei.

Moraes, em linhas gerais, tem uma visão otimista em relação ao direito e a sua capacidade de transformação social, rejeitando técnicas revolucionárias, como a greve. Porém, ele não se mostra cego quanto aos problemas reais que atingem mesmo aquelas situações, tais como a própria greve, em que já há previsão legal satisfatória e mesmo assim os problemas persistem. Isto é, no ponto específico em que o direito já era satisfatório e o problema ainda permanecia, através da atuação abusiva da polícia, o autor tem uma postura mais combativa.

\section{Considerações finais}

Em ambos os contextos comparados, início do século XX e duas primeiras décadas do século XXI, o direito e as relações sociais convivem com momentos de crise, o que significa dizer que novas relações jurídicas também são pensadas e criadas. Duas crises bastantes distintas, é verdade. De um lado, a crise ambiental e trabalhista dos anos recentes, que tem como principal exemplo a discussão sobre o neoextrativismo e seus impactos econômicos, sociais e jurídicos. De outro lado, o debate no começo do século XX sobre a questão social, sobre os novos desafios que o direito enfrentaria frente a problemas antes desconhecidos, relativos aos operários urbanos.

A resposta socialista para tais crises no meio jurídico também seguiu caminhos distintos que nos ajudam a entender um pouco sobre o contexto de cada período e o papel do direito em cada um deles. Juristas atuais, tais como Gustavo Seferian e Ricardo Prestes

\footnotetext{
${ }^{34}$ CORREIO DA MANHÃ. Rio de Janeiro. n. 1.863, 4 agosto, 1906a, p. 3.
} 
Pazello, com suas doutrinas sobre o uso tático do direito do trabalho e direito insurgente, respectivamente, compreendem o meio jurídico como um espaço de dominação em sua essência. Ambos, por caminhos diversos, pensam sobre como a função básica do direito é pacificar, o que induz necessariamente a uma dominação, ao controle de uma massa operária. Por esse motivo não enxergam soluções pautadas exclusivamente sobre o direito, isto é, o caminho jurídico não é a saída para os efetivos problemas sociais. Apesar disso, ambos entendem ser possível conquistas no meio jurídico, que podem auxiliar nas causas operárias. Em síntese, o direito, essencialmente, não é uma saída definitiva para a crise, mas é um meio para avanços intermediários e benéficos para a causa.

Evaristo de Moraes, por sua vez, um dos principais representantes do pensamento socialista no cenário jurídico da Primeira República no Brasil, tinha uma visão bem mais otimista e reformista sobre o direito e, em alguma medida, menos confiante sobre a atuação revolucionária no meio operário. Como explicado anteriormente, Moraes, ao longo de Apontamentos de Direito Operária, prega soluções - geralmente legislativas - para os problemas operários, afinal, o contexto ali ainda era de pouca proteção legislativa aos operários. Apenas na questão da greve, que já tinha, na visão de Evaristo de Moraes, uma solução legislativa satisfatória, é que ele se posicionava de maneira mais crítica acerca da aplicação daquela lei, reagindo, tanto em seu livro quanto em artigos escritos no Correio da Manhã, contra a atuação policial e administrativa. Mesmo nesse ponto específico, em que é mais crítico, Moraes, no Apontamentos, deixa claro seu ceticismo em relação às greves, entendendo que o caminho da sindicalização operária traz muito mais benefícios e é um estágio mais avançado de organização operária do que os movimentos grevistas. Em determinado trecho do livro o autor se refere às greves como "arma perigosa", evidenciando a sua percepção política antipática frente a esse instrumento.

Isso significa dizer, portanto, que mesmo entre um dos autores mais críticos em relação ao direito da Primeira República no Brasil, especialmente em relação ao direito operário e sua relação com o direito civil, está presente o que, na classificação proposta por Pazello, seria chamado de uso estratégico do direito; ou seja, a percepção de que o direito consegue responder às expectativas sociais de mudanças em momentos de crise. Isso significa dizer que as críticas ao papel do direito apontadas por Pazello e Seferian não tinham qualquer ressonância no Brasil do começo do século XX? Não creio que a questão seja temporal, mas especificamente sobre a visão socialista de Evaristo de Moraes. Inclusive, parte dessas críticas estavam presentes naquele contexto, ainda que expressas de formas 
diferentes e com significados diferentes. A minha hipótese, que merece ser pesquisada mais detalhadamente em outro trabalho, é que parte das posturas mais críticas eram dos anarquistas e não dos socialistas, como a proposta por Evaristo de Moraes.

Apesar disso, é preciso que se diga que a postura de Moraes não é exatamente uma surpresa. O contexto em que ele escreve Apontamentos de Direito Operário é de um período inicial no Brasil da construção daquilo que posteriormente se consolidará como a legislação social, sobretudo a partir da década de 1930, com o Governo Vargas. Evaristo de Moraes viveu um clima ainda de expectativa e esperança de que parte das soluções para os problemas sociais e do trabalho seriam resolvidos pela lógica interna do direito, o que foi se perdendo ao longo dos últimos anos do século XX com a crise dos direitos sociais e do Estado Social. 


\section{Referências Bibliográficas}

CAZZETTA, Giovanni. Lei e Estado Social: da legislação operária aos dilemas do welfaresem lei. Revista da Faculdade de Direito da UFRGS, Porto Alegre, n. 41, p.3-37, dez. 2019.

CORREIO DA MANHÃ. Rio de Janeiro. n. 1.863, 4 agosto, 1906a.

CORREIO DA MANHÃ. Rio de Janeiro. n. 1.996, 29 dezembro, 1906b.

COSTA, Pietro. I diritti sociali: un diagramma del loro sviluppo. In: CAPELLINI, Paolo; COSTA, Pietro; FIORAVANTI, Maurizio, et al. Iuris Quidditas: liber amicorum per Bernardo Santalucia. Napoli: Editoriale Scientifica, p. 37-53, 2011.

DECCA, Edgar S.. Ensaio sobre a memória anarquista: a história como ficção coletiva. História Oral, Rio de Janeiro, v. 2, p. 111-134, 1999.

FAUSTO, Boris. Trabalho urbano e conflito social. Rio de Janeiro: Difel, 1977.

GOMES, Ângela Maria de Castro. Burguesia e trabalho: política e legislação social no Brasil 1917-1937. Rio de Janeiro: Editora Campus LTDA., 1979.

KREIN, José Darin. O desmonte dos direitos, as novas configurações do trabalho e o esvaziamento da ação coletiva: consequências da reforma trabalhista. Tempo Social, v. 30, p. 77-104, 2018.

KUNTZ, Rolf. Os direitos sociais em xeque. Lua Nova: Revista de Cultura e Política, n. 36, p. 149-157, 1996.

MARX, Karl. O Capital [Livro I]: crítica da economia política. O processo de produção do capital. São Paulo: Boitempo, 2017.

MENDONÇA, Joseli Maria Nunes. Evaristo de Moraes: tribuno da República. $1^{\text {a }}$ ed. Campinas: UNICAMP, 2007.

MORAES, Evaristo de. Apontamentos de direito operário. $3^{\mathrm{a}}$ ed [ $1^{\mathrm{a}}$ ed. 1905]. São Paulo: LTr, 1986.

PAZELLO, Ricardo Prestes. Direito insurgente: fundamentações marxistas desde a América Latina. Revista Direito e Práxis, v. 9, p. 1555-1597, 2018.

SEFERIAN Scheffer Machado, Gustavo. Muito mais que "estudinhos": matriz privada do Direito do Trabalho e a atualidade dos "apontamentos de direito operário" de Evaristo de Moraes. In: PIOVESANA, C.U.M. et alii. (Org.). Seminário quem é quem no Direito do Trabalho. 1ed. São Paulo: LTr, v. 1, p. 15-23, 2019a.

SEFERIAN, Gustavo. Direito do trabalho como barricada: sobre o uso tático da proteção jurídica das trabalhadoras e trabalhadores. 1. ed. Belo Horizonte: RTM, 2021.

SEFERIAN, Gustavo. Onze proposições sobre o Direito do Trabalho desde a perspectiva ecossocialista. Teoria Jurídica Contemporânea, v. 4, p. 89-110, 2019 b.

SVAMPA, Maristella. As fronteiras do neoextrativismo na América Latina: conflitos socioambientais, digo ecoterritorial e novas dependências. Trad. Ligia Azevedo. São Paulo: Elefante, p. 23-74, 2019.

ZANIRATO, Silvia Helena. O descanso do guerreiro: um estudo sobre a instituição da Previdência Social no Brasil. Maringá: EdUem, 2003. 
Como citar este artigo: TEIXEIRA, Arley Fernandes. Os usos do direito e a questão social em Evaristo de Moraes. Revista de Ciências do Estado, Belo Horizonte, v. 6, n. 2, p. 1-18, 2021.

Recebido em 05.09.2021

Publicado em 18.12.2021

(cc) EY-Nc-sa Atribuição-NãoComercial-CompartilhaIgual 4.0 Internacional 